\title{
Su iza
}

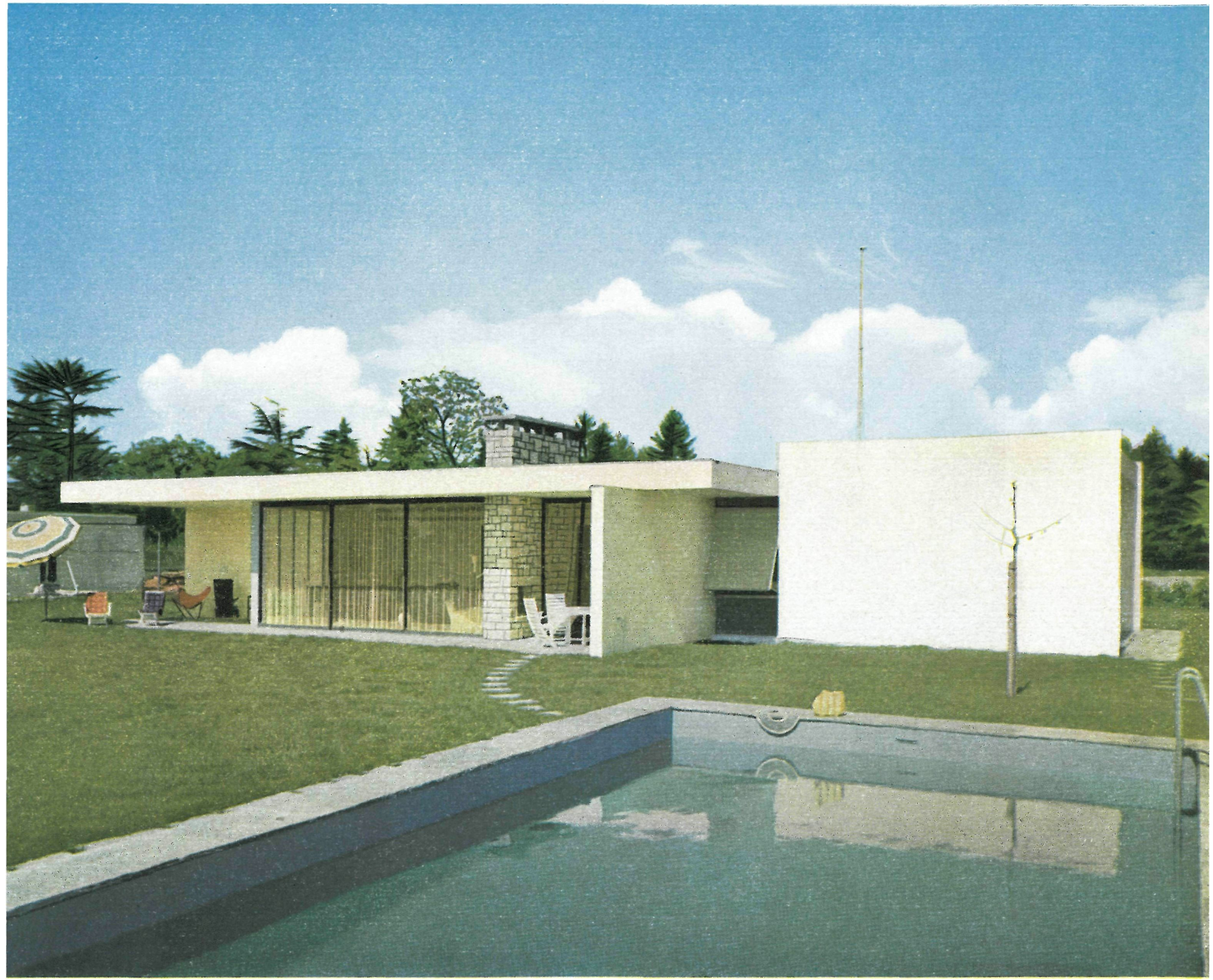

$161 \cdot 70$

\section{vivienda de un arquifecto}

LUC V. HERMÈS, arquitecto 


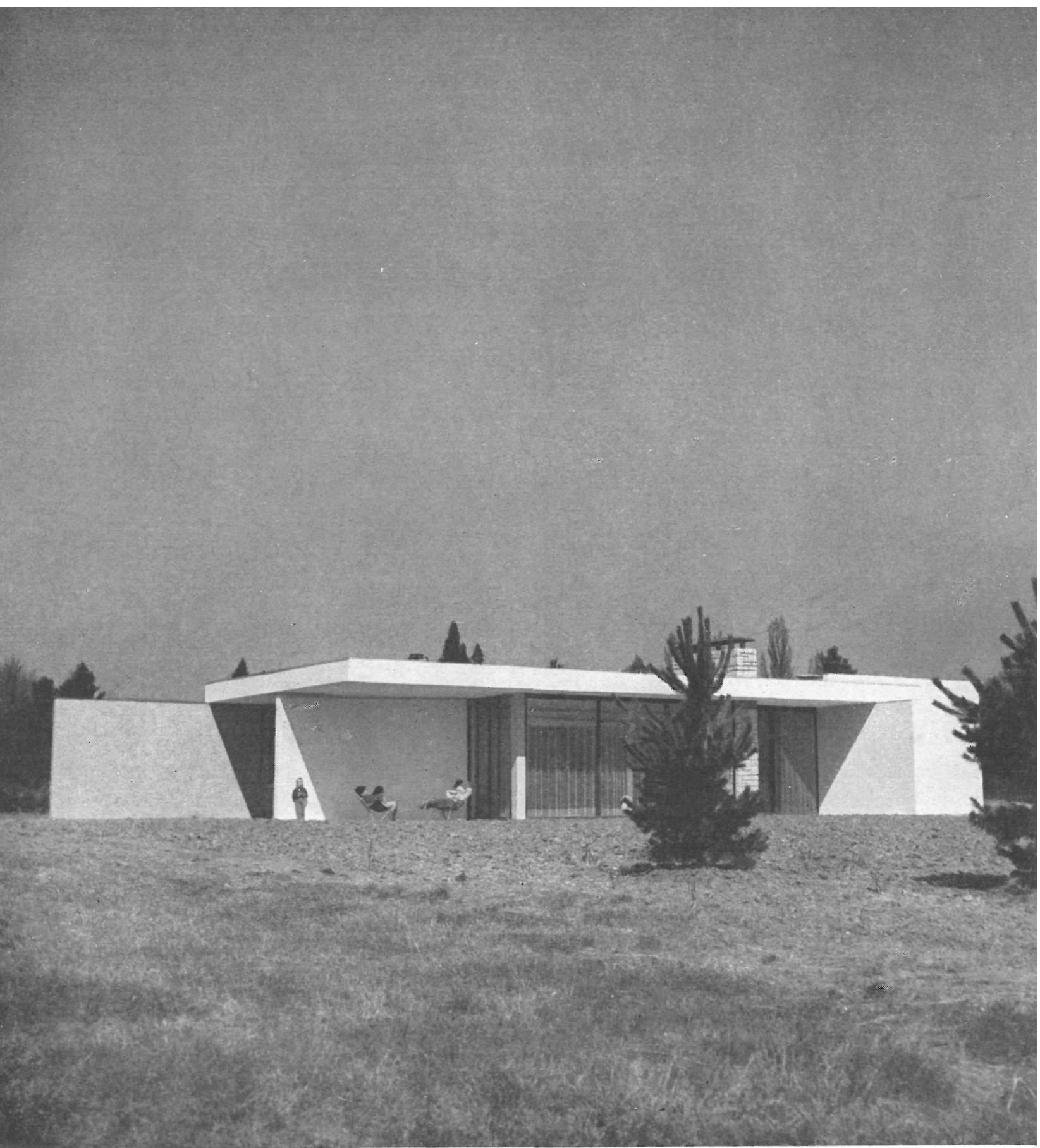

Sobre una pequeña colina que domina el lago de Ginebra y con fondo los Alpes Franceses, con el Mont Blanc en el centro, se ha construído su propia vivienda el arquitecto Hermès.

El programa se ha resuelto con planta en L, distinguiéndose en ella tres zonas claramente diferenciadas: recepción y dormitorio principal, al sur; habitaciones de niños con jardín de juego, a poniente; y el estudio de pintor y arquitecto y servicios, a norte.

La construcción se ha realizado con bloques «durisol», patente suiza existente en España, y con los que se obtiene un gran aislamiento térmico y acústico. Este material está formado por compresión de residuos de madera estabilizada, cemento y amianto; se colocan en obra en seco, elevando dos hiladas y rellenando los huecos centrales con hormigón, que puede ser armado. El arquitecto ha tratado de experimentar en toda la edificación materiales nuevos, tales como pavimentos de plástico continuo, bajantes de aglomerados de corcho y cemento, revestimiento interior de placas especiales, etc. 


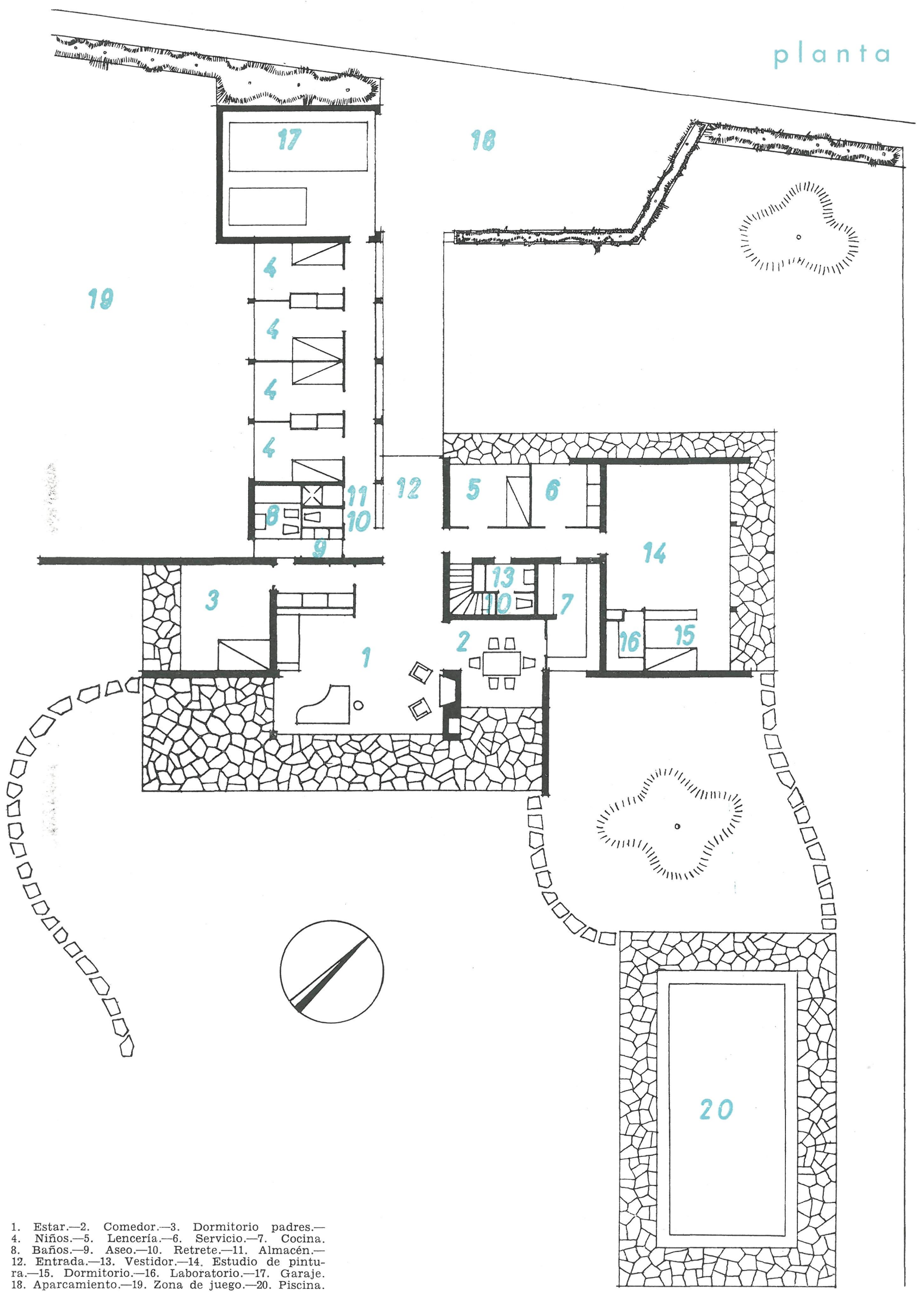




\section{exterior e interiores}

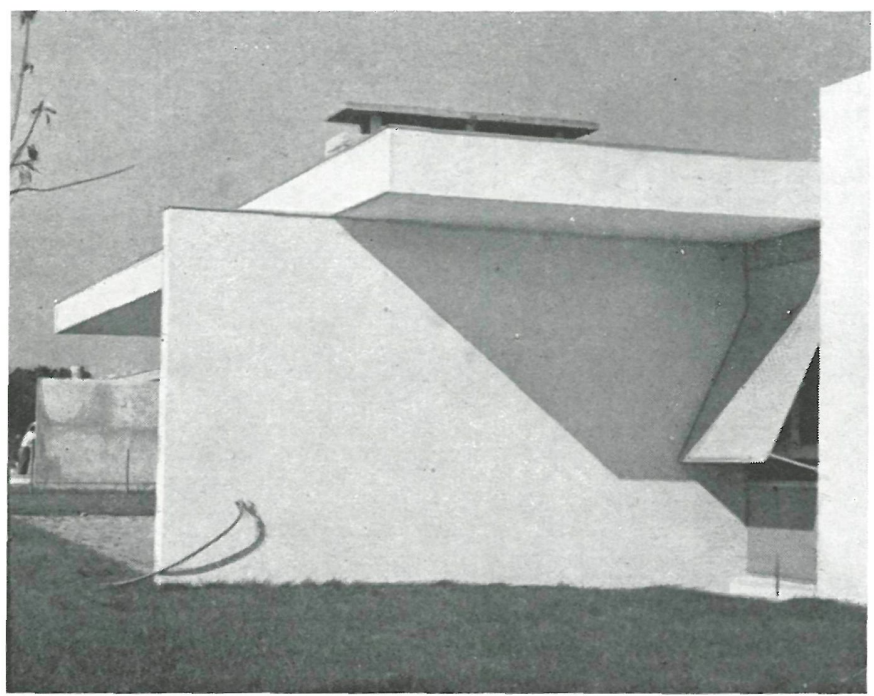

Fotos: MANDANIS

La cubierta vuela sobre la fachada; esto facilita la distribución de zonas de estar al aire libre, que amplían la superficie de vivienda en días de bonanza. Una chimenea exterior permite atemperar el ambiente en los atardeceres fríos del verano. La misma chimenea proporciona en el interior un segundo hogar en el estar.

Con la estudiada distribución de la planta se ha conseguido una vivienda en la que cada elemento tiene vida propia, con lo que sus cuatro hijos, de seis a veinte años, y ellos mismos, pueden gozar en un momento determinado de la independencia deseada.
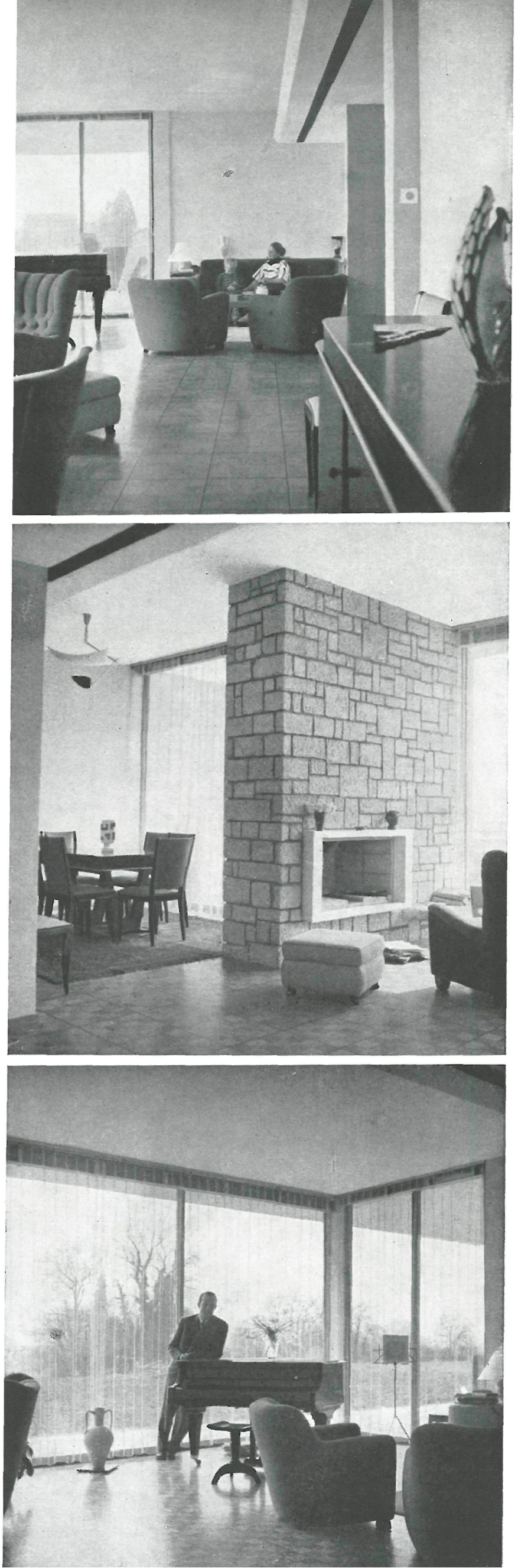